\title{
Research on Trend of Nutrients and its Response to Human Activities in the Pearl River Estuary
}

\author{
Yingxian Long*, Qiang Sun and Kun Yang \\ South China Institute of Environmental Science, Ministry of Ecology and Environment, Guangzhou 510655, China.
}

\begin{abstract}
This is a research on the change of nutrients and its structure in the Pearl River Estuary by the principal component analysis (PCA) according to the data and materials on water quality observation in the last 30 years around the Pearl River Estuary. Results showed that inorganic nitrogen (DIN) presented an obvious increase trend in the last 30 years, while phosphate and silicate presented an outstanding decrease trend in this area by the influence of human activities. The average N/P ratio increased by 1.44 times, the $\mathrm{Si} / \mathrm{N}$ ratio decreased by $66.8 \%$, the $\mathrm{Si} / \mathrm{P}$ ratio decreased by $18.5 \%$, and the structure of nutrients changed significantly. According to the results of PCA, the first two principal components (PC) were extracted. PC1 was associated with GDP, population, industrial output value and wastewater discharge, which explained $80.9 \%$ of the variance. PC2 was characterized by cultivated land area, which explained $14.6 \%$ of the variance. It indicates that the change of nutrients content and structure in the Pearl River Estuary was closely related to economic development and industrial pollution discharge, and the effect of the change of land use and land cover on the change of nutrients should not be ignored.
\end{abstract}

\section{Introduction}

The estuarine coast is the sensitive area by the land-sea interaction and it is also the area significantly influenced by human activities ${ }^{[1-2]}$. In recent decades, with the increasing intensity of human activities, a large number of nutrients have been transported from the land to the ocean by river runoff, which has been leading to the degradation of the Marine environment and the change of biogeochemical processes, especially in the estuaries and bays where the eutrophication, hypoxia ad various pollution problems occur frequently ${ }^{[3-6]}$. The Pearl River Estuary receives an average annual inflow of 326 billion $\mathrm{m}^{3}$ by $452,000 \mathrm{~km}^{2}$, which is one of the estuaries with the highest intensity of human activities around China. At present, most of the studies on the long-term evolution trend of nutrient in the Pearl River Estuary are concentrated in the part of Lingdingyang Bay or the entire northern part of the South China Sea. However, little attention has been paid to the whole coastal waters around the Pearl River Estuary and the factors and drivers affecting to the changes still lack of systematic, comprehensive and quantitative studies.

This paper analyzes the change of nutrient content and the tendency of its structure change in the last 30 years based on the Mann-Kendall and Daniel Trend Test Method by adopting the principal component analysis and regression analysis on the population agglomeration, industrial and living sewage, agricultural production, land use change and other human activities on the nutrient drive which provides the scientific basic for the control strategies on Marine pollution.

\section{Research Area and Methods}

\subsection{Overview of Research Area}

The coastal waters of the Pearl River Estuary studied in this paper are the eight entrances of the Pearl River Estuary and the relevant waters located in $21^{\circ} 52^{\prime} \sim 22^{\circ} 46^{\prime} \mathrm{N}, \quad 112^{\circ} 58^{\prime} \sim 114^{\circ} 03^{\prime} \mathrm{E}$. The main administrative regions involved include Guangzhou, Shenzhen, Zhuhai, Foshan, Jiangmen, Dongguan, Zhongshan and other prefectural cities.

\subsection{Methods}

According to the environmental monitoring data and relevant studies of the Pearl River Estuary waters in the last 30 years (1980-2014), the time series of inorganic nitrogen, active phosphate and silicate nutrients in the Pearl River Estuary waters have been established. The Mann-Kendal Test Method has been adopted to analyze the long-term change trend of nutrient concentration and structure. The effects of economic and social development on the nutrient change in the coastal areas of the Pearl River Estuary have been analyzed by the principal component analysis and regression analysis. Data sources are divided into two categories: one is the related literature of the Pearl River Estuary and the other is the research data collected annually by Guangdong Environmental Monitoring Stations in the years 2002 to

$\overline{{ }^{*} \text { Corresponding author: longyingxian@ }}$ scies.org 
2014. The locations of Monitoring Stations are shown in Figure 1. All the data have been calculated and analyzed by the Software SPSS 12.0.

\section{Results and Analysis}

\subsection{Trend of Inorganic Nutrient Concentration}

In the past 30 years, the annual average concentration of inorganic nitrogen in the sea water in the Pearl River Estuary presented a uptrend of inverted " $\mathrm{N}$ " type and the annual average concentration of both active phosphate and silicate decreased significantly and then remained basically unchanged (Figure 1). During the 25a from 1990 to 2014, the average annual concentration of inorganic nitrogen increased almost double as $8.36 \mu \mathrm{mol} / \mathrm{L}$; the average annual concentration of active phosphate and silicate decreased by over $60 \%$ as $0.53 \mu \mathrm{mol} / \mathrm{L}$ and $57.31 \mu \mathrm{mol} / \mathrm{L}$. The trend of inorganic nitrogen and active phosphate was high in Spring and Summer, low in Autumn and Winter but the regularity of silicate was not obvious. Ammonia nitrogen and nitrate nitrogen, especially ammonia nitrogen, are the main forms of inorganic nitrogen in the seawater.
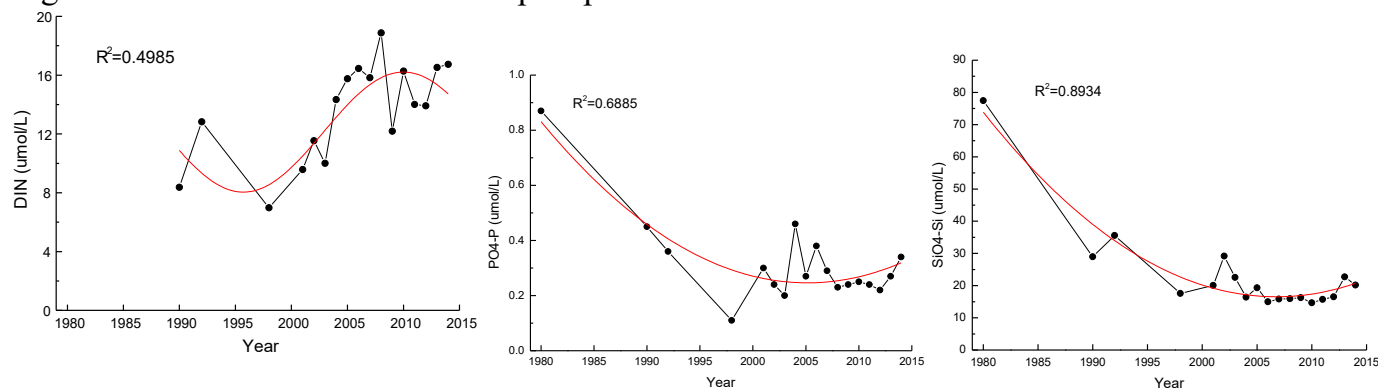

Figure 1. Variation of inorganic nitrogen concentration

In 2014, the area of high average annual inorganic nitrogen concentration in the Pearl River Estuary is larger than before, even covering the whole Lingdingyang whose high average area is nearby the outlet to Humen and the sea near Shenzhen Bay and Shenzhen Estuary is next to it. The annual concentration of active phosphate decreases from the eastern waters of Lingdingyang to the west and the one in the estuary is higher than that at the coastal waters and gradually decreases to the open sea area. There is an obvious high value area in the waters near the Shenzhen Estuary. Compared with the spatial distribution characteristics of nutrients in 2004 and 2014, it was found that the average annual inorganic nitrogen concentration in the central and western waters of the Pearl River Estuary has decreased from the nearshore to the open sea waters around 10 years ago with that the concentration has not changed much. This is mainly due to the reciprocating movement in the Pearl River Estuary, which leads to the nutrients remained in the coastal waters that had been imported from the land sources of the eight ports. The high annual concentration area of active phosphate has been transferred from the north of Lingdingyang to the eastern sea. The plane distribution of average annual silicate concentration has not changed much. Around 10 years, the average annual concentration of silicate decreases from the inner Lingdingyang Ocean to the outer Ocean. It has been decreased from the entrance to offshore to the open sea gradually and the high average annual concentration of silicate showed in the waters near the Shenzhen Estuary and the waters near Huangmao Sea maricultural area are next to it.

According to analyzing on the trend of average concentration of inorganic nitrogen, active phosphate and silicate in the Pearl River Estuary from 1990 to 2014, the results show that inorganic nitrogen present an extremely significant upward trend while silicate and active phosphate showed and extremely significant downward trend at the level of $a=0.01$. The growth rate of inorganic nitrogen was $0.285 \mu \mathrm{mol} / \mathrm{L} \cdot$ year $^{-1}$, the decrease rate of active phosphate was $0.0 .17 \mu \mathrm{mol} / \mathrm{L} \cdot$ year $^{-1}$ and the decrease rate of silicate was $1.617 \mu \mathrm{mol} / \mathrm{L} \cdot$ year $^{-1}($ Table $1)$.

Table 1. Significance test and annual average change rate of inorganic nutrient content

\begin{tabular}{ccccc}
\hline Index & $\begin{array}{c}\text { M-K Value } \\
(\mathrm{Z})\end{array}$ & $\begin{array}{c}\text { Daniel Value } \\
\left(\mathrm{r}_{\mathrm{s}}\right)\end{array}$ & $\begin{array}{c}\mathrm{P} \\
\text { Value }\end{array}$ & $\begin{array}{c}\text { Annual average change rate } \\
\left(\mu \mathrm{mol} / \mathrm{L} \cdot \mathrm{year}^{-1}\right)\end{array}$ \\
\hline Inorganic Nitrogen & 2.72 & $0.426^{* *}$ & $<0.01$ & 0.285 \\
Active Phosphate & -2.06 & $-0.313^{*}$ & $<0.01$ & -0.017 \\
Silicate & -3.49 & $-0.473^{* *}$ & $<0.01$ & -1.617 \\
\hline
\end{tabular}

\subsection{Spatiotemporal Variation of Nutrient Ratio}

Since the 1990s, the N/P ratio in the Pearl River Estuary has basically increased rapidly and then remained stable (Figure 2). From 1990 to 2014, N/P had increased by 1.44 times. The average annual concentration of inorganic nitrogen in 2014 was about 2.0 times on that in 1990 , indicating that the increase of N/P ratio was mainly determined by the increase of inorganic nitrogen concentration. The $\mathrm{Si} / \mathrm{N}$ ratio basically showed a trend rapid decline and then slow rise (Figure 2). Since 2004, the average annual $\mathrm{Si} / \mathrm{N}$ ratio has basically remained at about 1.0. In near 25a from 1990 to 2014, Si/N dropped by $66.8 \%$. Si $/ \mathrm{P}$ ratio basically shoed a trend of rising first and then falling while its changing trend is close to the normal distribution (Figure 2). In near 35a from 1980 to 2014, Si/P had decreased by $39.7 \%$ and $\mathrm{Si} / \mathrm{P}$ ratio had 
dropped by $18.5 \%$ in about 25a from 1990 to 2014 . According to the standard of nutrient chemometrics threshold proposed by Justic and Dorch, the nutrient
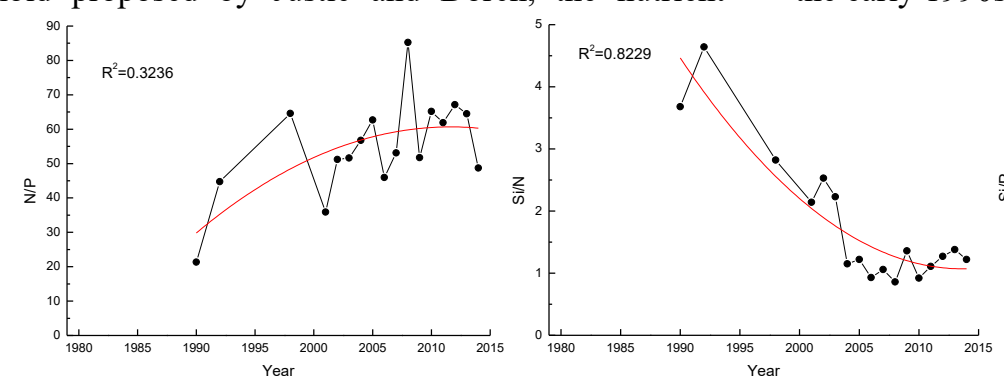

structure in the Pearl River Estuary waters has changed from the limitation of nitrogen, phosphorus and silicon in the early 1990s to the limitation of phosphorus.

Figure 2. Change trends of inorganic nitrogen ratio

According to analyzing on the trend test of the time series and the changing trend of average nutrient ratio in the Pearl River Estuary in each season from 1990 to 2014, the results showed that $\mathrm{Si} / \mathrm{N}$ value had been present as a significant declining trend at the level of $a=0.01$. Si $/ \mathrm{P}$ value showed an obvious decrease trend at the level of $a=0.05$ but the change of N/P value was not obvious. The annual decline rates of $\mathrm{Si} / \mathrm{N}$ and $\mathrm{Si} / \mathrm{P}$ values were 0.104 units/ year and 1.065 units/ year (Table 2).

Table 2. Significance test and annual average change rate of inorganic nutrient ratio

\begin{tabular}{|c|c|c|c|c|}
\hline Index & $\begin{array}{l}\text { M-K Value } \\
\text { (Z) }\end{array}$ & $\begin{array}{l}\text { Daniel Value } \\
\left(\mathrm{r}_{\mathrm{s}}\right)\end{array}$ & P Value & $\begin{array}{l}\text { Annual average change rate } \\
\left(\text { unit } \cdot \text { year }^{-1}\right)\end{array}$ \\
\hline $\mathrm{N} / \mathrm{P}$ & 1.07 & 0.279 & 0.064 & - \\
\hline $\mathrm{Si} / \mathrm{N}$ & -3.12 & $-0.464^{* *}$ & $<0.01$ & -0.104 \\
\hline $\mathrm{Si} / \mathrm{P}$ & -1.56 & $-0.310^{*}$ & $<0.05$ & -1.065 \\
\hline
\end{tabular}

factors affecting the long-term change of nutrients in the

\subsection{Nutrients Response to the Human Activities}

Based on the environmental factor analysis, 16 social economic indicators have been selected to analyzing with long-term trend of nutrient, which are GDP, population, cultivated land areas, the farmgate quantity, amount of applying nitrogen, phosphorus content, fresh water aquaculture, maricultural capacity, vegetable production, industrial emissions, agricultural water, industrial water, living water consumption, construction land area of emissions, industrial wastewater, sewage and so on. These indicators represent the impact of human activities on industry, agriculture and life. For there was not monitoring in the nutrient survey in 1980s, by consideration on the whole environmental quality and socioeconomic mathematical integrity, time series from 1990, 1992, 1998, 2001 to 2014 were uniformly selected for the correlation analysis.

The correlation analysis results show that there is a significant correlation to the change of nutrient between GDP, population, cultivated land area, freshwater culture, sewage discharge and industrial wastewater. Among them, cultivated land area has significant correlation with nutrient change, which may be because the increase of cultivated land area will reduce the nutrient load carried into the sea by the surface runoff and that thus inhibited the growth of phytoplankton. It shows that surface runoff is the main source of nutrient into the sea and the underlying surface type is one of the important factors affecting eutrophication in the Pearl River Estuary. Inorganic nitrogen and active phosphate have significant or extremely significant correlation with GDP, population and other social and economic indicators, indicating that human economic and social activities are the important

\section{Pearl River Estuary waters.}

By principal component analysis, it is conducted that the contribution rate of principal component 1 to the total variance was $80.91 \%$, which was the leading influencing factor of nutrient changes in the Pearl River Estuary. GDP, population, fresh water aquaculture volume and domestic swage discharge were relatively weighted. Among them, to specific, GDP, population, freshwater aquaculture amount, construction land area and domestic sewage discharge had positive effects on principal component 1, meanwhile, cultivated land area had negative effects on principal component 1 (Table 3 ). The principal component 1 can be regarded as the pollution pressure index brought by population agglomeration. This shows that with the rapid growth and development of economy and society in the coastal areas of the Pearl River Estuary, the concentration of population brings about the increase of pollutant discharge pressure and the improvement of living standards also leads to the change of land us pattern and the increase of consumption of agricultural and sideline products. The contribution rate of principal component 2 to the total variance was $14.58 \%$, which was an important factor influencing the change of nutrient in the Pearl River Estuary. It mainly represented the discharge of industrial wastewater that can be regarded as the pollution pressure of industrial development in the coastal areas of the Pearl River Estuary waters (Table 3). 
Table 3. Loadings of variables

\begin{tabular}{ccc}
\hline Index & Component 1 $(\mathrm{F} 1)$ & Component 2(F2) \\
\hline GDP & 0.985 & -0.095 \\
Population & 0.953 & -0.240 \\
Cultivated Land Areas & -0.978 & 0.126 \\
Fresh Water Aquaculture & 0.882 & 0.044 \\
Construction Land Areas & 0.880 & 0.333 \\
Living Water Consumption & 0.936 & -0.308 \\
Industrial Water & 0.463 & 0.856 \\
\hline
\end{tabular}

Regression analysis was used to analyze the relationship between the influencing factors and the principal components. The results showed that GDP was the most corelated with the principal component 1 $(p<0.01)$ while the correlation coefficient between GDP and principal component 1 was the largest, followed by the correlation coefficient between cultivated land area and construction land area with the principal component 1. It indicated that the economic development of the coastal area of the Pearl River Estuary was the main driving factor of the nutrient around that waters while the pollution pressure caused by the change of land use was also great. The discharge of industrial wastewater was most correlated with principal component $2(\mathrm{p}<0.01)$, indicating that the discharge of industrial water pollution was the main cause of industrial pollution pressure.

\section{Discussion}

The above studies showed that the nutrient concentration and structure had changed significantly with the increase of human activity intensity in the Pearl River Estuary water. It was presented as follows: firstly, the content of inorganic nitrogen in the Pearl River Estuary fluctuated and increased, while the content of active phosphate and silicate decreased especially from 2002 to 2008. The change of nutrient structure had become the second. The $\mathrm{N} / \mathrm{P}$ value increased as the whole while the $\mathrm{Si} / \mathrm{N}$ value continued to decrease and its value stayed around 1.0 at the time that $\mathrm{Si} / \mathrm{P}$ value fluctuated and decreased. This indicated that the nutrient structure of the Pearl River Estuary had changed from nitrogen, phosphorus and silicon in the early 1990s to phosphorus.

Land source pollution is one of the main causes of environmental pollution in the Pearl River Estuary. According to the Bulletin on Marine Environmental Quality issued by Guangdong Province from 2004 to 2014, the nutrient carried into the sea by the Pearl River had generally increased in the shape of " $\mathrm{N}$ " as increasing first and then decreasing since 2004 (Figure 3). In the 11a from 2004 to 2014, the flux of nutrients into the sea had increased by almost 5 times and a high concentration of nutrients especially inorganic nitrogen had been led by a large number of nutrients generated through human activities along with runoff in the Pearl River Estuary.

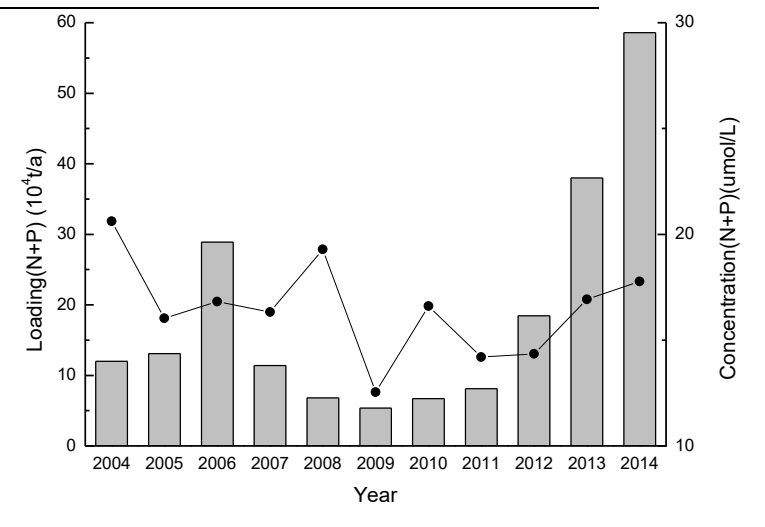

Figure 3. Nutrient flux from river and nutrient concentration in the Pearl River Estuary

According to the analysis of environmental statistics of Guangdong Province, $82.53 \%$ of the waste water and $78.31 \%$ of the ammonia nitrogen came from the urban sources in point of land areas along the Pearl River Estuary. Nitrogen and phosphorus from domestic sewage were discharged into rivers and coastal areas and had become an important source of nutrients in the Pearl River Estuary. Compared with the urban population, sewage discharge, domestic source of ammonia nitrogen emissions from 2000 to 2014, the population increased by $34.43 \%$, the discharge of domestic sewage had doubled, and the discharge of domestic ammonia nitrogen increased by $54.99 \%$, which had led to the great input of the nitrogen around the Pearl River Estuary. The GDP, population, cultivated land area, construction land area, fresh water culture amount, domestic sewage discharge, industrial wastewater discharge and other socio-economic indicators in the coastal areas in the Pearl River Estuary were significantly correlated with the inorganic nitrogen and active phosphate but less related to the silicate. It showed that the economic and social activities of human beings were the important factors affecting the environmental changes in the Pearl River Estuary. According to the principal component analysis, GDP, population, freshwater aquaculture amount and domestic sewage discharge were the first principal component affecting the change of nutrients in the Pearl River Estuary waters and the industrial wastewater discharge was the second principal component, both of which totally accounted for $95.49 \%$ of the results. By the regression analysis, economic development and industrial sewage discharge were the main driving factors for the long-term change of nutrients and ocean acidification in the Pearl River Estuary waters and the influence of the change of land use on the nutrients can not be ignored either. 
The marine environment is influenced by both natural and human activities and mechanism of nutrients change is complex and changeable. In this paper, the research on the nutrients changes focuses on the response to human activities but not considered sufficiently on the influence by natural factors (such as tidal current and water depth), biological processes (such as chlorophyll a) and endogenous factors (such as sediments) in the sea areas. The research results only raise the driving factors of human activities and the mechanism and influencing sources of nutrients changes can be further studied in the future.

\section{Conclusion}

In the past 30 years, the nutrient content in the Pearl River Estuary waters showed different changes as the inorganic nitrogen content with an extremely significant increase trend while the phosphate and silicate content with an extremely significant decrease trend. The $\mathrm{Si} / \mathrm{N}$ and $\mathrm{Si} / \mathrm{P}$ values in the Pearl River Estuary showed a significant decline trend but the N/P variation trend was not significant, which was characterized by phosphorus limitation. Principal component analysis and regression analysis showed that economic development and industrial sewage discharge were the main driving factors for the long-term changes of nutrients around the Pearl River Estuary waters while the effect by the change of land use cannot be ignored either. The regularity and trend of nutrients concentration and change of their structures in the Pearl River Estuary should be paid attention to, especially on the control of the growth of inorganic nitrogen.

\section{References}

1. Seitzinger S P, Harrison J A, Dumont E, et al. Sources and delivery of carbon, nitrogen, and phosphorus to the coastal zone: An overview of Global Nutrient Export from Watersheds (NEWS) models and their application [J]. Global Biogeochemistry Cycles, 2005,19: GB4S01.

2. Halpern B S, Walbridge S, Selkoe K A, et al. A global map of human impact on marine ecosystems[J]. Science, 2008, 319: 948-952.

3. Qu H J, Kroeze C. Past and future trends in nutrients export by rivers to the coastal waters of China[J]. Science Total Environment, 2010,408:2075-2086.

4. Cloern J E. Phytoplankton bloom dynamics in coastal ecosystems: A review with some general lessons from sustained investigation of San Francisco Bay, California [J]. Reviews of Geophysics, 1996,34: 127-168.

5. Turner R E, Rabalais N N. Coastal eutrophication near the Mississippi River delta [J]. Nature, 1994, 368: 619-621.

6. Yin $\mathrm{K}$, Qian $\mathrm{P} \mathrm{Y}, \mathrm{Wu} \mathrm{MC}$, et al. Shift from $\mathrm{P}$ to $\mathrm{N}$ limitation of phytoplankton biomass across the Pearl
River estuarine plume during summer [J]. Marine Ecological Progress Series, 2001, 201:65-79. 